\title{
The Impact of Sevoflurane and Propofol Anesthesia on Cerebral Blood Flow in Pediatric Open Cardiac Surgery, a Comparative Randomized Study
}

\author{
Ahmed M Farid ${ }^{1}$, Hani I Mohamed ${ }^{1 *}$, Sabry RA ${ }^{2}$ and Saher I Taman ${ }^{3}$ \\ 1Department of Anesthesia and Surgical Intensive Care, Mansoura University, Egypt \\ ${ }^{2}$ Department of Pediatric Cardiothoracic Surgery, Mansoura University, Egypt \\ ${ }^{3}$ Department of Diagnostic and Interventional Radiology, Mansoura University, Egypt
}

*Corresponding author: Hani I Taman, Department of Anesthesia and Surgical

\section{Research Article \\ Volume 4 Issue 4}

Received Date: November 08, 2019

Published Date: December 11, 2019

DOI: $10.23880 /$ accmj-16000165

Intensive Care, Faculty of Medicine, Mansoura University, UK, Tel: 07534268934; Email: hani_taman@yahoo.com

\section{Abstract}

Background: Despite improvements in open cardiac surgical techniques and implementation of effective neuroprotective strategies, the brain, an organ highly sensitive to hypoxia, is still threatened by thromboembolic ischemic stroke, hemorrhage, or inflammation during CPB. Cerebral air embolization and hypoperfusion are considered as fundamental causes for these neurological complications. Transcranial Doppler can determine any air emboli entering brain circulation intra-operatively. Together with cerebral oximetry, they can detect any harmful embolic events during open cardiac surgery. New models of neuroprotective strategies were implanted to ameliorate this problem including different anesthetic medications like propofol and sevoflurane.

Methods: 100 patients who were planned for elective cardiac surgery were recruited in this study. Anesthesia was maintained with Propofol infusion at a rate of $150 \mu \mathrm{g} / \mathrm{Kg} / \mathrm{min}$ or sevoflurane $1 \mathrm{MAC}$. Transcranial Doppler sonography was used to monitor cerebral blood flow, and oxygenation with evaluation of their neurocognitive function using ages \& stages questionnaire.

Results: Cerebral blood flow maximum velocity was higher in seveoflurane group when compared to propofol group at insertion and removal of aortic cannula as well as on release of aortic cross clamp. Mean arterial pressure and mean velocity of middle cerebral blood flow were higher in sevoflurane group when compared with propofol group. Also velocity mean were lower in comparison to basal values in propofol group. ages \& stages questionnaire score comparison between both groups was of no significant difference.

Conclusion: in comparison to sevoflurane, propofol decrease the maximum cerebral blood flow velocity, mean cerebral blood flow velocity and MAP more than sevoflurane. Meanwhile, it has equivalent effect to sevoflurane regarding neurocognitive outcome. 


\section{Anaesthesia \& Critical Care Medicine Journal}

Keywords: Neurological complications; Pediatric; Open cardiac surgery; Cognitive domains; Hypoperfusion; Embolization; Transcranial Doppler; Cerebral oximetry; Neuroprotective strategies; Pharmacological neuroprotective

Abbreviations: TCD: Transcranial Doppler; CPB: Cardiopulmonary Bypass; CBFV: Cerebral Blood Flow Velocity; MES: Micro-Emboli Signals; SPSS: Statistical Package for Social Scientists; SD: Standard Deviation; IQR: Interquartile Range.

\section{Introduction}

Cardiac surgery is associated with postoperative complications such as (cardiac, neurological, pulmonary and acute renal failure) and prolonged care in the hospital. These neurological deficits are mostly subclinical with optimistic long term outcome, however cognitive impairments may continue to affect the neurological development and daily life [1,2]. Cognitive domains including attention, memory, learning, visual, motor skills, and executive function may be affected alone or accompanied by behavioral change. As hippocampus is the main part responsible for memory, this might explain why all of cognitive problems, anterograde memory deficits are mostly reported after cardiac surgery [3].

Mechanisms of brain injury related to perioperative processes are not fully characterized, Three principle factors were demonstrated; cerebral hypoperfusion, cerebral arterial embolization, and systemic inflammatory response following CPB [4]. All these mechanisms were rooted mainly to air embolization and hypoperfusion. Air emboli presence in the cerebral circulation intraoperatively can reduce cerebral perfusion and obstruct blood flow by either direct mechanical effect or by increasing platelets aggregation and thrombus formation. [5-8].

In addition, circulating gaseous bubbles may induce functional endothelial injury with transient, increased permeability to macro and micro molecules. Moreover, a rise in brain water uptake, glucose utilization and protein extravasation are also associated with gaseous emboli [9]. Experimental cerebral air embolism is found to have a two-step effect on the brain. Shortly after air entry, there is multifocal brain lesion with widening of the extracellular space, later shrinkage and necrosis of neurons and neuronal sheath [10].

The origin of tiny emboli may originate frombubble oxygenators, venous reservoirs, air in the CPB venous line, inadequate surgical deairing in open chamber procedures, introduction by perfusionist during drug administration and collection of blood samples, and entrainment of air into the blood in the cardiotomy suction and vacuum assisted drainage [11]. Cooling causes of microbubbles inside somatic blood vessels $[12,13]$.

Currently, advanced monitors represent a fundamental tool for early recognition and implantation of preventive measures against embolic events. Transcranial Doppler ultrasound (TCD) is a sensitive, real-time monitor of cerebral blood flow velocity (vCBF) and emboli during congenital heart surgery. Currently available instruments use pulsed-wave ultrasound at 2 $\mathrm{MHz}$ frequency, which is range-gated, emits a power of $100 \mathrm{~mW}$, and has a sample volume length of up to $15 \mathrm{~mm}$. A display of the frequency spectrum of Doppler signals is easily interpreted, and peak systolic and mean flow velocities, in $\mathrm{cm} / \mathrm{second}$, and pulsatility index are displayed [14]. Although detecting these tiny bubbles in Cardiopulmonary Bypass (CPB) lines is easy nowadays, no previous studies have investigated the possibility of cerebral air embolization during open cardiac surgery and the implications of anesthetic drug on their incidence [15].

Cerebral oximetry with TCD can detect any harmful injurious agents including real-time detection and quantification of microemboli passing through the cerebral circulation in pediatric patients undergoing open cardiac surgery using CPB [11].

Aiming at improving neurological outcome and specifically emboli reduction, new models of neuroprotective strategies were implanted. These include better design of venous reservoirs, increased uptake of CPB arterial line filters, increased surgeon's' awareness about air embolism impact, cell saver processing of cardiotomy blood, meticulous perfusionist interventions, cooling, retrograde cerebral perfusion and adequate surgical deairing of all cardiac chambers [11]. Also, pharmacological neuroprotective strategies were recruited including, hyperbaric oxygen, barbiturate coma, lidocaine, oxygen and inotropic support and some anesthetic agents as well $[16,17]$. 


\section{Anaesthesia \& Critical Care Medicine Journal}

One of the common anesthetic drug used in neuroprotective method is propofol which causes inhibition of glutamate release, reduction in cerebral metabolic rate oxygen consumption with cerebral vasoconstriction $[18,19]$. Sevoflurane is widely used in neuroanesthesia and shows an intrinsic dose-dependent cerebral vasodilatory effect. Several studies, have demonstrated how it increases the cerebral blood flow velocity (vCBF) and decreases the cerebrovascular resistance (CVR) in a dose-dependent manner [20,21]. With the affordability of many methods to decrease cerebral gaseous embolization, it is difficult to assess whether the use of specific anesthetic agent can attenuate the embolic events.

In this study, we hypothises that propofol is more effective than sevoflurane in reducing the cerebral blood flow velocity in pediatric patients undergoing open heart surgery for congenital heart diseases with better neurocognitive functions outcomes. The principle aim of this study was to assess the effect of two different anesthetic medications (propofol and sevoflurane) on decreasing the cerebral blood flow velocity the Middle Cerebral circulation during open cardiac surgery using CPB.

\section{Patients and methods}

This double-blind, randomized, comparative study was conducted on 100 patients of either sex aged 4-7 years who were subjected to elective correction of simple congenital heart diseases using cardiopulmonary bypass after obtaining an informed written consent from their parents/guardians. Patient with neurological, hepatic or renal diseases were excluded from the study. Preoperative clinical examination and laboratory tests were full field according to our unit protocol. On arrival to operative theatre, patients were randomly assigned (using closed envelope method) into two groups: propofol group and sevoflurane group.

Standard monitoring (ECG, $\mathrm{SpO}_{2}$ and NIBP) were connected to all patients before induction of anesthesia. Supplemental oxygen was provided via a face mask (using Datex monitor, Helsinki, Finland AS). One peripheral intravenous indwelling cannula were inserted in nondominant hand after using EMLA cream to numb the insertion place.

Anesthesia was induced using I.V. fentanyl $5 \mu \mathrm{g} / \mathrm{Kg}$, propofol 2- 2.5mg/Kg (in propofol group) or sevoflurane 3-4MAC (in sevoflurane group). With loss of consciousness, patients were mechanically ventilated by positive pressure ventilation via face mask at a rate of 18-
25 breathes per minute with $100 \% 02$ and $1 \mathrm{mg} / \mathrm{kg}$ rocuronium I.V. was given for ETT insertion. A triple lumen central line was inserted under complete aseptic condition in right internal jugular vein. An arterial line was inserted in right hand to monitor MAP at certain intervals, and facilitate blood sampling. Nasopharyngeal temperature probe, cerebral oximetry, entropy probe as well as transcranial Doppler transducer were attached to the patient head for adequate monitoring. End-tidal $\mathrm{CO}_{2}$ was monitored by side-stream capnograph. Anesthesia was maintained with Propofol infusion at a rate of $150 \mu \mathrm{g} / \mathrm{Kg} / \mathrm{min}$ (in propofol group) [22] or sevoflurane 1 MAC (in sevoflurane group) and fentanyl $1 \mu \mathrm{g} / \mathrm{Kg} / \mathrm{min}$, to maintain state and response entropy reading between 40 45 and blood pressure within $75 \%$ of its basal value with additional doses of rocuronium $(0.5 \mathrm{mg} / \mathrm{Kg})$ to maintain muscle relaxation. A pressure controlled mode was used to ventilate all patients aiming at tidal volume $6-8 \mathrm{ml} / \mathrm{kg}$ and end tidal $\mathrm{CO}_{2}$ between $30-35 \mathrm{mmHg}$.

The preload was gradually increased by reducing the venous return to CBP, and transoesophogeal echo was used to monitor and confirm the de-airing process. After completion of weaning from $\mathrm{CPB}$, the left ventricle vent was stopped and clamped in situ [23].

Transcranial doppler (TCD) sonography to monitor the velocities of blood flow in middle cerebral artery (CBFV), and incidence of air embolization through trans temporal window, a 2.0/2.5 MHz TCD device (Toshiba Xeario model, $3 \mathrm{MHz}$ frequency). Although cerebral blood flow velocity is not a direct measurement of $\mathrm{CBF}$, but changes in CBFV is closely correlate with the cerebral blood flow changes because the middle cerebral artery diameter is usually constant [24].

Mean velocity of flow was measured before induction of general anesthesia (basal), after insertion of aortic cannula, 15 minutes after establishment of $\mathrm{CPB}$, on removal of cross clamp, and removal of aortic cannula. Emboli detection was done at different event markers; after insertion of aortic cannula, 15 minutes after establishment of $\mathrm{CPB}$, after removal of cross clamp, and removal of aortic cannula. Event-related micro-emboli signals (MES) were defined as the micro emboli signals that were spotted within 180 second following an event marker. Another experienced radiographer had reevaluated all stored Doppler signal events in a different cession $[22,23,25]$.

A research with experience in administration of neuropsychological tests were recruited for neurocognitive function assessment in this study using the age 


\section{Anaesthesia \& Critical Care Medicine Journal}

and sex questionnaire. which was designed for assessing the severity of impairments, and identifying changes in cognitive dysfunctions in a wide age range (3-14 years). Moreover, comprehension of instructions was independent of socioeconomic status and educational level. $[28,29]$. To familiarize the children with the test, we gave an explanation trial and perform a basal assessment for all participants. Postoperative cognitive function assessments were conducted in the ward or at anaesthesia clinic after one week and three months after surgery.

\section{Sample Size}

Sample size of this study was calculated using PS software for Windows version 10 according to differences in number of microemboli detected in previous study. It revealed 54 patients in each arm to obtain power of about $80 \%$. We increased the number of patients up to 60 patients in each arm to compensate $20 \%$ possible dropouts [30].

\section{Statistical Analysis}

Statistical analysis was done using statistical package for social scientists (SPSS) program version 17, USA, Chicago. The mean and standard deviation (SD) were reported as appropriate for continuous data after checking data for normality using the Shapiro-Wilk test. Independent sample $t$ test or Mann-Whitney $U$ test were used to compare perioperative differences between groups. Chi-square test were used for qualitative data. P $<0.05$ was considered significant (Tables $1 \& 2$ ).

\begin{tabular}{|c|c|c|}
\hline & Propofol Group (n=50) & Sevoflurane Group (n=50) \\
\hline Age (years) & $5.13 \pm 0.67$ & $5.38 \pm 0.76$ \\
\hline Sex Male & $70 \%(15)$ & $60 \%(31)$ \\
\hline Female & $30 \%(13)$ & $40 \%(19)$ \\
\hline Weight (kilogram) & $24.50 \pm 4.03$ & $25.25 \pm 3.47$ \\
\hline ASD & $50 \%(25)$ & $45 \%(22)$ \\
\hline VSD & $50 \%(25)$ & $55 \%(28)$ \\
\hline
\end{tabular}

Table 1: Demographic data of the studied groups: Data are presented in number \& $\%$ or mean \pm SD.

All patients have completed the study successfully with no dropouts. No considerable differences were observed between two groups as regard demographic data and type of surgery.

\begin{tabular}{|c|c|c|}
\hline & PropofolGroup (n=50) & SevofluraneGroup (n=50) \\
\hline Cross Clamp Time (min) & $31.7 \pm 8.57$ & $35.95 \pm 20.72$ \\
\hline CPB Time (min) & $28.9 \pm 9.92$ & $29.65 \pm 10.62$ \\
\hline
\end{tabular}

Table 2: Aortic cross clamp time ( $\mathrm{min}$ ) and CPB time (min) in the studied groups, Data are in mean \pm SD.

Both cross clamp time and CPB time were almost the same in both groups (Table 2).

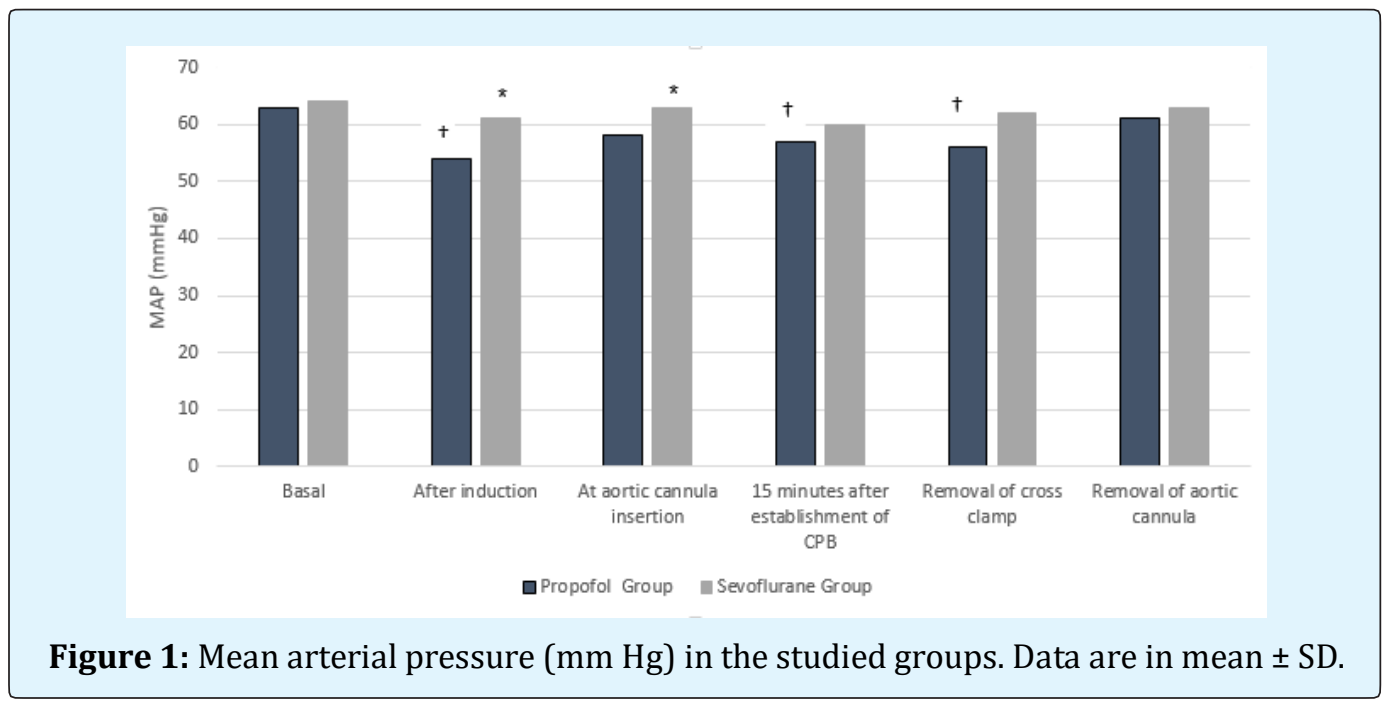




\section{Anaesthesia \& Critical Care Medicine Journal}

Mean arterial pressure showed statistically higher values in sevoflurane group when compared with propofol group after induction and at aortic cannula insertion. Also mean arterial pressure was statistically lower in propofol group when compared to basal value after induction, 15 minutes after establishment of CPB and after removal of cross clamp.

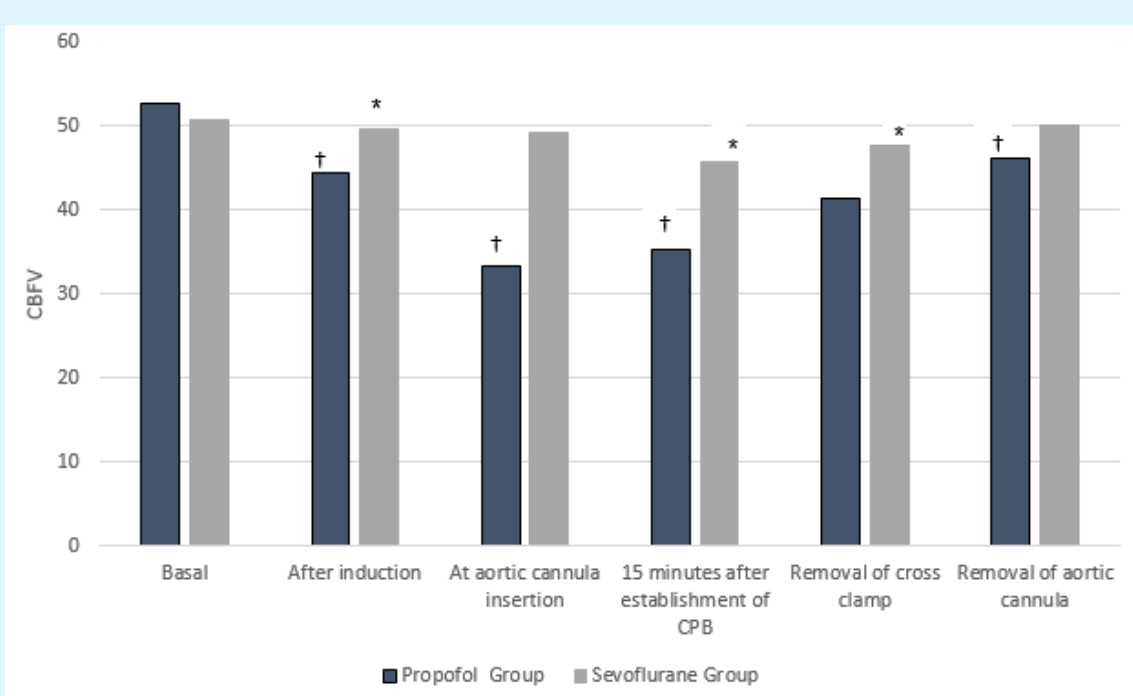

Figure 2: Mean Velocity $(\mathrm{cm} / \mathrm{s})$ of middle cerebral blood flow in the studied groups. Data are in mean \pm SD.

Velocity mean was significantly higher at aortic cannula insertion, 15 minutes after establishment of CPB and on removal of crossclamp in sevoflurane group when compared with propofol group. Also In propofol group, velocity mean were lower in comparison to basal values after induction, at aortic cannula insertion, 15 minutes after establishment of CPB and on removal of cross clamp.
The average number of embolic events detected within 180 second following every events were higher in seveoflurane group when compared to propofol group at insertion and removal of aortic cannula as well as on release of aortic cross clamp.

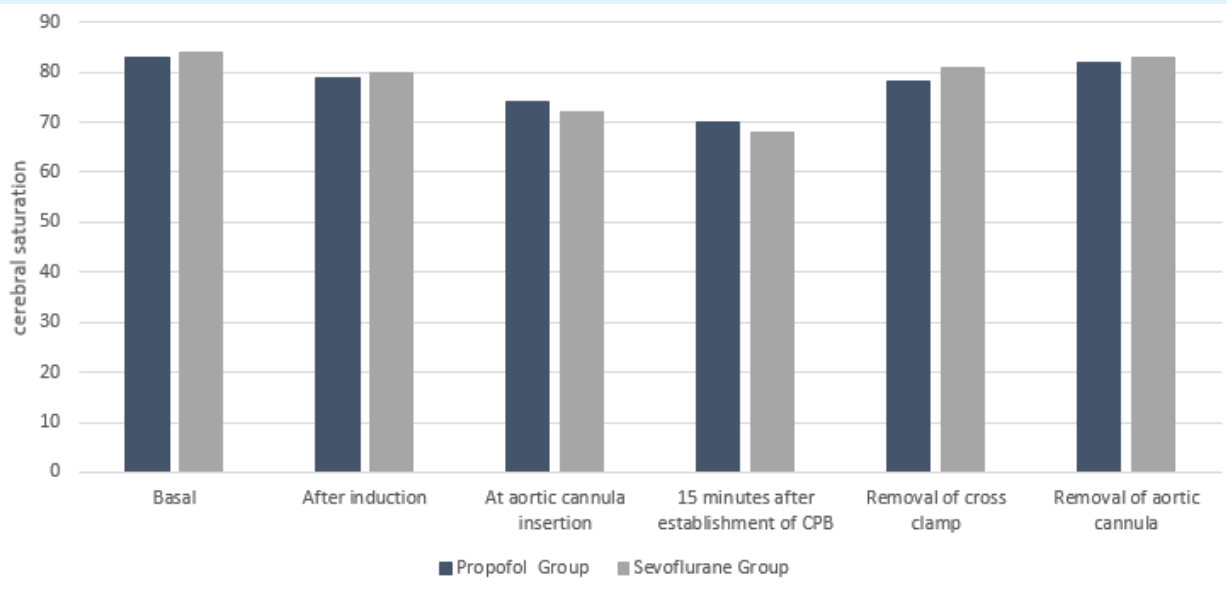

Figure 3: cerebral oxygen saturation of the studied groups (\%). Data are in mean \pm SD. 


\section{Anaesthesia \& Critical Care Medicine Journal}

Cerebral oxygen saturation showed no differences between both groups throughout the surgery (Figure 3).

\begin{tabular}{|c|c|c|}
\hline & Propofol Group & Sevoflurane Group \\
\hline Before surgery & $36.15 \pm 3.63$ & $36.55 \pm 6.12$ \\
\hline 1 week after surgery & $30.17 \pm 5.13$ & $30.16 \pm 4.28$ \\
\hline 3 months after surgery & $35.69 \pm 4.10$ & $34.25 \pm 4.45$ \\
\hline
\end{tabular}

Table 3: Neuro-cognitive function assessment results of the studied groups. Data are in mean \pm SD.

The mean average of age and sex questionnaire results statistically insignificant between both groups. However the mean value was slightly lower after one week of surgery and improved by time to be almost near normal three months after surgery in both groups (Table 3).

\section{Discussion}

There is a need to identify new strategies to prevent harmful events during cardiothoracic surgery. Neuroprotection may occur as a consequence of reduced $\mathrm{O}_{2}$ demand, enhanced $\mathrm{O}_{2}$ delivery, or attenuation of pathologic processes that contribute to cellular injury or death [31]. Neurological brain affection during cardiac surgery can be caused by air bubbles when enter the cerebral circulation intra-operatively [5]. Anesthetic agents are considered as a part of pharmacological preventive measures against air bubbles and brain protective effects.

In this study, all patients in propofol anaesthesia group showed significant reduction in the maximum and mean cerebral blood flow velocity (CBFV) more than patients in sevoflurane anaesthesia group. In addition the mean arterial blood pressure were significantly lower in propofol group than sevoflurane group. There were no differences between the two groups as regard cerebral oxygen saturation and the postoperative neurocognitive function outcome.

According to this study, lower cerebral blood flow velocity and MAP were associated with propofol based anaesthesia when compared to sevoflurane group. The lower maximum cerebral blood flow velocity in propofol group than sevoflurane group can be explained by different mechanisms; the Vasoconstrictor effect of propofol on small arterioles in cerebral circulation. This propofol mediated vasoconstrictor effect increases the resistance force inside small arterioles in arterial side which hinder the smooth passage of foreign materials into cerebral circulation. Propofol causes reduction in CBF which decreases the cerebral regional blood flow with subsequent attenuation of the carrying power and driving force of blood flow to foreign objects including air emboli [32]. The reduction in cerebral blood flow velocity caused by propofol within the cerebral arterial tree can be explained by decreasing the cerebral metabolic rate of oxygen, and suppressing effect on endotheliumdependent relaxation that might reduce the steady-state CBF velocity $[33,34]$. This leads to decrease the driving force of blood flow associated with lower its carrying ability. This is attributed to decrease in SVR, negative inotropic effect, and resetting of baroreceptors caused by propofol $[32,34,35]$.

On the other hand, a higher load of air emboli was noticed in sevoflurane group. All volatile anesthetic agents cause direct cerebral vasodilatation to different degrees. Desflurane and sevoflurane are more potent cerebral vasodilator than other volatile agents. This vasodilataion with loss of autoregulation decreases the vascular resistance to blood flow with any foreign objects inside. Also sevoflurane Increases cerebral metabolic rate with associated increase or non-significant changes in the global and regional blood flow as well. In addition, sevoflurane maintain MAP with maintenance of the driving force of blood flow to all organs including the brain [36-38]. Sevoflurane is not associated with increases in heart rate, whereas increasing concentrations of sevoflurane slightly decrease blood pressure, myocardial contractility and reduces baroreflex function [39]. In the current study, CBFV was decreased between $13-17 \%$ by propofol effect. This study is very similar to the work published by Panel et al., in which the impact of propofol infusion $(6 \mathrm{mg} / \mathrm{kg} / \mathrm{h}$ for $40 \mathrm{~min}$ ) on CMRO2 was evaluated. He observed a reduction in $\mathrm{CBF}$ and $\mathrm{CMRO}_{2}$ with propofol without affecting arteriovenious oxygen delivery, suggesting maintenance of normal cerebral circulation and metabolism [40].

In another study by Newman et al., he tried to evaluate the embolic preventive and brain protective effect of propofol. He did not defined a fixed rate for propofol infusion but took an $80 \%$ suppression of EEG as a target point and he reported reduction of cerebral blood flow, embolic exposure, cerebral oxygen delivery and metabolic rate both in normothermia and hypothermia [33]. 


\section{Anaesthesia \& Critical Care Medicine Journal}

Regarding sevoflurane, cerebral blood flow was increased by only $1-2 \%$. Kuroda, et al. in his study proved that sevoflurane has cerebral vasodilator effect and can increases CBFV and embolic load which matches the present study [41]. Previous reports indicated that sevoflurane between 0.5-1.0 MAC has minimal vasodilating effect on small brain arterioles and has no systemic hemodynamic effects at the most common used 1 MAC sevoflurane [39,42]. In our study, CBFV was lower in propofol group relative to sevoflurane group. Similarly, previous work by Kaike, et al. has assessed the effect 1 MAC, 1.5, and 2 MAC of sevoflurane and $0 \mu \mathrm{g} / \mathrm{ml}, 6 \mu \mathrm{g} / \mathrm{ml}$, $9 \mu \mathrm{g} / \mathrm{ml}$, and $12 \mu \mathrm{g} / \mathrm{ml}$ TCI of propofol on regional cerebral blood flow on volunteers. He reported that both anesthetics medications caused a global decrease of $\mathrm{rCBF}$ however this reduction was grater in propofol more than sevoflurane [43]. Kaisti, et al. in their study comparing effects of sevoflurane, propofol, and adjunct nitrous oxide on regional cerebral blood flow, oxygen consumption, and blood volume in humans by using positron emission tomography tracers, reported that propofol reduced $\mathrm{rCBF}$ more than sevoflurane but reduces rCMRO2 only to an extent similar to sevoflurane [44].

Another study by Engelhard found that propofol caused cerebral vasoconstriction, intact cerebrovascular autoregulation and maintained $\mathrm{CO}_{2}$ reactivity. On the other hand sevoflurane caused cerebral vasodilatation, decreased CPP, impaired cerebrovascular autoregulation and maintained $\mathrm{CO}_{2}$ reactivity; and hence supporting our findings [45]. In this study, we hypothise that propofol would associated with better neurological outcome than sevoflurane, however the results showed no significant differences in neurocognitive outcome between propofol and sevoflurane groups. This may be attributed to the facts that propofol decreases cerebral embolic events, conserve cerebrovascular autoregulation regardless metabolism and mitigates intracranial pressure [46-48]. In addition propofol can attenuate glutamate-mediated excitotoxic mechanisms by either decreasing NMDA receptor activation, reducing glutamate release, or or increasing glutamate uptake into neuronal and glial cells. In also potentiates GABAergic neuronal activity [49] and has antioxidant activit [50]. Meanwhile, sevoflurane exhibit its neuroprotective effect by a dose dependant reduction in cerebral metabolic requirements, or related to decreased apoptotic cell death in the post-ischemic period [51,52]. Alteration of body temperature during cooling on CBP that decreased the $\mathrm{CMRO}_{2}$, changes in $\mathrm{PaCO}_{2}$ that may affect $\mathrm{CBF}$ and autoregulation mechanisms and small size of microemboli (less than 200 micron) that was not large enough to occlude the small arterioles [53].
Similarly, During this study, it was noticed that the rate of incidence of air emboli is higher in both groups on right middle cerebral artery than left one. We suggested that proximity, size and early origin of brachiocephalic trunk from the aortic arch facilitate trapping and passage of air emboli from left ventricle to cerebral blood vessels on right side.

In conclusion, in comparison to sevoflurane, propofol decrease the Maximum; mean cerebral blood flow velocity, embolic events and MAP to a great extent than sevoflurane. Meanwhile, it has equivalent effect to sevoflurane regarding regional cerebral oxygen saturation and neurocognitive outcome.

\section{References}

1. Bayram H, Hidiroglu M, Cetin L, Kucuker A, Iriz E, et al. (2013) Comparing S-100 protein levels and neurocognitive functions between patients undergoing on-pump and off-pump coronary artery bypass grafting. J Surg Res 182(2): 198-202.

2. Stroobant N, van Nooten G, Belleghem Y, Vingerhoets G (2002) Short-term and long-term neurocognitive outcome in on-pump versus off-pump CABG. Eur J Cardiothorac Surg 22(4): 559-564.

3. Marasco SF, Sharwood LN, Abramson MJ (2008) No improvement in neurocognitive outcomes after offpump versus on-pump coronary revascularisation: A meta-analysis. Eur J Cardiothorac Surg 33(6): 961970.

4. Mora CT, Murkin JM (1995) the central nervous system: Responses to cardiopulmonary bypass. In: Mora CT, (Eds.), Cardiopulmonary Bypass: Principles and Techniques of Extracorporeal Circulation. New York: Springer-Verlag pp: 114-146.

5. Barak M, Katz Y (2005) Microbubbles: pathophysiology and clinical implications. Chest 128(4): 2918-2932.

6. Ward CA, McCulloch D, Fraser WD (1987) Relation between compliment activation and susceptibility to decompression sickness. J Applied Physiol 62(3): 1160-1166.

7. Thorsen T, Brubakk A, Ovstedal T, Farstad M, Holmsen H (1986) A method for production of N2 micobubbles in platlet rich plasma in an 


\section{Anaesthesia \& Critical Care Medicine Journal}

aggregometer like apparatus, and effect on platelet density in vitro. Undersea Bio Rese 13(3): 271-288.

8. Fox KAA (1992) Reperfusion injury: laboratory phenomenon or clinical reality? Cardio Res 26(7): 656-659.

9. Haller C, Sercombe R, Verrecchia C, Fritisch H, Seylaz J, et al. (1987) Effect of the muscarinic agonist carbachol on pial arteries in vivo after endothelial damage by air embolism. J Cerebral Blood Flow\& metabolism 7(5): 605-611.

10. Julio G, Igor K, Thomas A, Albert L (1981) Arterial Air Embolism: Structural Effects on the Gerbil Brain. Stroke 12(4): 414-421.

11. Willcox TW, Mitchell SJ (2009) Microemboli in our bypass circuits: A contemporary audit. J Extra Corpor Tech 41(4): 31-38.

12. Barbosa NF, Cardinelli DM, Ercole FF (2010) Postoperative complications of cardiovascular surgery with cardiopulmonary bypass Complicaciones en el posoperatorio de cirugía cardiovascular con circulation extracorporeal. Arq Bras Cardiol 95(6): 151-158.

13. Lelis RGB, Auler Jr JO (2004) Pathophysiology of Neurological Injuries during Heart Surgery. Rev Bras Anestesiol 54(4): 607-617.

14. Lynch JE, Riley JB (2008) Microemboli detection on extracorporeal bypass circuits. Perfusion 23(1): 2332.

15. Mackinnon AD, Aaslid R, Markus HS (2004) Longterm ambulatory monitoring for cerebral emboli using transcranial Doppler ultrasound. Stroke 35(1): 73-81.

16. Shrinivas VG, Sankarkumar R, Rupa S (2004) Retrograde cerebral perfusion for treatment of air embolism after valve surgery. Asian Cardiovasc Thorac Ann 12(1): 81-82.

17. Ziser A, Adir Y, Lavon H, Shupak A (1999) Hyperbaric oxygen therapy for massive arterial air embolism during cardiac operations. J Thorac Cardiovasc Surg 117(4): 818-821.

18. McCormack JG (2008) Total intravenous anaesthesia in children. Curr Anaesth \& Cri l Care 19(5-6): 309314.
19. Koerner IP, Brambrink AM (2006) Brain protection by anesthetic agents. Curr opi anaesthesiol 19(5): 481-487.

20. Holmstrom A, Akeson J (2005) Sevoflurane induces less cerebral vasodilation than isoflurane at the same A-line autoregressive index level. Acta anaesthesiol Scand 49(1): 16-22.

21. Wong GT, Luginbuehl I, Karsli C, Bissonnette B (2006) The effect of sevoflurane on cerebral autoregulation in young children as assessed by the transient hyperemic response. Anesth Analg 102(4): 10511056.

22. Steur RJ, Perez RS, De Lange JJ (2004) Dosage scheme for propofol in children under 3 years of age. Paediatr Anaesth 14(6): 462-469.

23. Al-Rashidi F, Blomquist S, Hoglund P, Meurling C, Roijer A, et al. (2009) A new de-airing technique that reduces systemic microemboli during open surgery: $A$ prospective controlled study. J Thorac Cardio Surg 138(1): 157-162.

24. Bishop CC, Powell S, Rutt D, Browse NL (1986) Transcranial Doppler measurement of middle cerebral velocity: a validation study. Stroke 17(5): 913-915.

25. Schoenburg M, Baer J, Schwarz N, Stolz E, Kaps M, et al. (2006) Embo Dop: insufficient automatic microemboli identification. Stroke 37(2): 342-343.

26. Hugh S Markus (2000) Transcranial Doppler ultrasound. British Medical Bulletin56 (2): 378-388.

27. Boussuges A, Molenat F, Carturan D, Gerbeaux P, Sainty JM (1999) Venous gas embolism: Detection with pulsed Doppler guided by two-dimensional echocardiography. Acta Anaesthesiol Scand 43(3): 328-432.

28. Crum RM, Anthony JC, Bassett SS, Folstein MF (1993) Population-based norms for the Mini-Mental State Examination by age and educational level. JAMA 269(18): 2386-2391.

29. Folstein MF, Folstein SE, McHugh PR (1975) "Minimental state": a practical method for grading the cognitive state of patients for the clinician. J Psychiatr Res 12(3): 189-198. 


\section{Anaesthesia \& Critical Care Medicine Journal}

30. T S Padayachee, S Parsons, R Theobold, J Linley, R G Gosling, et al. (1987) The detection of microemboli in the middle cerebral artery during cardiopulmonary bypass: a transcranial Doppler ultrasound investigation using membrane and bubble oxygenators. Ann Thorac Surg 44(3): 298-302.

31. Dineen NE, Brodie FG, Robinson TG (2010) Continuous estimates of dynamic cerebral autoregulation during transient hypocapnia and hypercapnia. Journal of applied physiology. 108(3): 604-617.

32. Darwish RS, Ahn E, Amiridze NS (2008) Role of transcranial Doppler in optimizing treatment of cerebral vasospasm in subarachnoid hemorrhage. Journal of intensive care medicine 23(4): 263-270.

33. Oshima T, Karasawa F, Satoh T (2002) Effects of propofol on cerebral blood flow and the metabolic rate of oxygen in humans. Acta anaesthesiol Scand 46(7): 831-836.

34. Monk CR, Coates DP, Prys-Roberts C, Turtle MJ, Spelina K (1987) Haemodynamic effects of a prolonged infusion of propofol as a supplement to nitrous oxide anaesthesia. Studies in association with peripheral arterial surgery. Br J anaesthesia 59(8): 954-960.

35. Turner BK, Wakim JH, Secrest J, Zachary R (2005) Neuroprotective effects of thiopental, propofol, and etomidate. AANA J 73(4): 297-302.

36. Sponheim S, Skraastad O, Helseth E, Due Tønnesen B, Aamodt G, et al. (2003) Effects of 0.5 and 1.0 MAC isoflurane, sevoflurane and desflurane on intracranial and cerebral perfusion pressures in children. Acta anaesthesiolo Scand 47(8): 932-938.

37. Goettel N, Patet C, Rossi A, Burkhart CS, Czosnyka M, et al. (2016) Monitoring of cerebral blood flow autoregulation in adults undergoing sevoflurane anesthesia: a prospective cohort study of two age groups. J Clin Monit Comput 30(3): 255-264.

38. Marianna J, Levente M, Béla F, Tamás V, Dénes $P$, et al. (2019) Effect of sevoflurane on systemic and cerebral circulation, cerebral autoregulation and $\mathrm{CO} 2$ reactivity. BMC Anesthesiol 19: 109-117.

39. Ebert TJ, Harkin CP, Muzi M (1995) Cardiovascular responses to sevoflurane: a review. Anesth Analg 8(6): 11-22.
40. Panel L, Laaksonen M, Kallioinen J, Långsjö T, Laitio A, et al. (2002) Effects of propofol on cerebral blood flow and the metabolic rate of oxygen in humans. Acta Anaesthesiol Scand 46(7): 831-836.

41. Kuroda Y, Murakami M, Tsuruta J, Murakawa T, Shiroyama Y (2000) Effects of sevoflurane and isoflurane on the ratio of cerebral blood flow/metabolic rate for oxygen in neurosurgery. J Anesth 14(3): 128-132.

42. Kadoi Y, Takahashi K, Saito S, Goto F (2006) The comparative effects of sevoflurane versus isoflurane on cerebrovascular carbon dioxide reactivity in patients with diabetes mellitus. Anesth Analg 103(1): 168-172.

43. Kaike K, Liisa M, Mika T, Vesa O, Sargo A (2002) Effects of Surgical Levels of Propofol and Sevoflurane Anesthesia on Cerebral Blood Flow in Healthy Subjects Studied with Positron Emission Tomography. Anesth 96(6): 1358-1370.

44. Kaisti KK, Langsjo JW, Aalto S, Oikonen V, Sipilä H, et al. (2003) Effects of sevoflurane, propofol, and adjunct nitrous oxide on regional cerebral blood flow, oxygen consumption, and blood volume in humans. Anesth 99(3): 603-613.

45. Engelhard K, Werner C (2009) The effects of general anesthesia and variations in hemodynamics on cerebral perfusion. Appl cardio pathophysiol 13: 157166.

46. Koerner P, Brambrink M, Ansgar M (2006) Brain protection by anesthetic agents. Current opinion in anaesthesiology 19(5): 481-487.

47. Crespo JLM (1998) Anesthesia for the Surgery of Intracranial Aneurysms: Part IV. The Inter Anesth 2(4): 5580 -5587.

48. Kawaguchi M, Furuya H, Patel PM (2005) Neuroprotective effects of anesthetic agents. J Anesth 19(2): 150-156.

49. Adembri C, Venturi L, Pellegrini-Giampietro DE (2007) Neuroprotective effects of propofol in acute cerebral injury. CNS drug reviews 13(3): 333-351.

50. Williams B, Akabas H (2002) Structural evidence that propofol stabilizes different GABA(A) receptor states at potentiating and activating concentrations. The J 


\section{Anaesthesia \& Critical Care Medicine Journal}

neuroscience: the official journal of the Society for Neuroscience 22(17): 7417-7424.

51. Inoue S, Davis P, Drummond C, Cole J, Patel M (2006) The combination of isoflurane and caspase 8 inhibition results in sustained neuroprotection in rats subject to focal cerebral ischemia. Anesth and analgesia 102(5): 1548-1555.

52. Toner C, Stamford J (1996) General anesthetics as neuroprotective agents. In: Bailliere T, (Eds.),
Bailliere's Clinical Anesthesiology International pratice and research UK: Saunders pp: 515-538.

53. Borger A, Peniston M, Weisel D, Vasiliou M, Green E, et al. (2001) Neuropsychologic impairment after coronary bypass surgery: effect of gaseous microemboli during perfusionist interventions. J thoracic and cardio surg 121(4): 743-752. 